\title{
Photocatalytic reactor for organic compound removal using photocatalytic mechanism
}

\author{
S T T LE ${ }^{1,2}$, W KHANITCHAIDECHA ${ }^{1,2}$ and A NAKARUK ${ }^{3,4, *}$ \\ ${ }^{1}$ Department of Civil Engineering, Faculty of Engineering, Naresuan University, Phitsanulok 65000, Thailand \\ ${ }^{2}$ Centre of Excellence for Innovation and Technology for Water Treatment, Naresuan University, \\ Phitsanulok 65000, Thailand \\ ${ }^{3}$ Department of Industrial Engineering, Faculty of Engineering, Naresuan University, Phitsanulok 65000, Thailand \\ ${ }^{4}$ Center of Excellence for Environmental Health and Toxicology, Naresuan University, Phitsanulok 65000, Thailand
}

MS received 15 October 2014; accepted 20 October 2015

\begin{abstract}
In this work, a photocatalytic reactor with a working volume of $13 \mathrm{l}$ was fabricated of soda-lime silica glass. Commercial titanium dioxide $\left(\mathrm{TiO}_{2}\right)$ particles were used as the photocatalyst and trails were conducted on the photodecomposition of methylene blue (MB) solutions $\left(10^{-5} \mathrm{M}\right)$. The activation of the photocatalysts was carried out using $5 \mathrm{UV}$ lamps $(378 \mathrm{~nm}, 36 \mathrm{~W})$, and $13 \mathrm{~g}$ of $\mathrm{TiO}_{2}$ was added each week to the reactor. The MB solution was fed at a flow rate of $0.87 \mathrm{l} \mathrm{h}^{-1}$, while the effluent was removed after $5 \mathrm{~h}$ of hydraulic retention time. The performance of the reactor was studied over a period of 45 days. The results showed a sharp decline in the dissolved oxygen (DO) concentration and $\mathrm{pH}$ of the solution with the increased addition of $\mathrm{TiO}_{2}$ to the reactor owing to the occurrence of the photocatalytic process. The reactor was found to be highly effective in decomposing MB solution. The performance was observed to slightly decrease over the long operating period owing to the $\mathrm{TiO}_{2}$ accumulation on the reactor wall, and its non-participation in the reactions.
\end{abstract}

Keywords. Titanium dioxide; photocatalysis; methylene blue; wastewater treatment.

\section{Introduction}

During the past several decades, researchers have increasingly investigated the properties and applications of titanium dioxide $\left(\mathrm{TiO}_{2}\right)$ for applications such as solar-electric conversion [1], self-cleaning surfaces [2], pigments [3], water splitting [4] and water purification [5]. Of these, water purification is one of the most common application of the photocatalytic properties of $\mathrm{TiO}_{2}$. The resultant oxidation process can be used for the degradation of organic contaminants. $\mathrm{TiO}_{2}$ is commonly used for the photocatalytic process owing to advantages such as high chemical stability, non-solubility and high photocatalytic activity.

There have been several works that have focussed on the use of $\mathrm{TiO}_{2}$ for organic contaminant removal [6-10], with the major focus being on the mechanisms involved in enhancing the efficiency of removal. However, there has been limited research on determining the efficiency of the materials over long periods. Therefore, for investigating the long-term photocatalytic efficiency in degrading organic pollutants, a laboratory-scale photocatalytic column reactor, consisting of $\mathrm{TiO}_{2}$ particles (anatase phase) as the catalyst and 5 UV-lamps (378 nm wavelength) as the light source was set up. The degradation of methylene blue (MB) solution was used as the standard for determining the photocatalytic efficiency and the testing was carried out for a period of 45 days.

*Author for correspondence (auppathamn@nu.ac.th)

\section{Methodology}

The photocatalytic reactor used was fabricated from sodalime silica glass and was cuboidal in shape with dimensions of $6 \mathrm{~cm} \times 15 \mathrm{~cm} \times 150 \mathrm{~cm}$ and a total working volume of 131 . The reactor system consisted of 5 UV lamps $(378 \mathrm{~nm}$, $36 \mathrm{~W})$, magnetic stirring system and a pumping system. The photocatalytic material used was commercial $\mathrm{TiO}_{2}$ (SigmaAldrich), the characteristic of $\mathrm{TiO}_{2}$ particles are described in the previous work [11], $13 \mathrm{~g}$ of which was mixed with the wastewater, with the water being supplied from the bottom of the reactor at a flow rate of $0.87 \mathrm{l} \mathrm{h}^{-1}$. The treated water was continuously removed from the top of the reactor after a hydraulic retention time of $5 \mathrm{~h}$. The time of retention was maintained at $5 \mathrm{~h}$ based on previous results by the authors [11] that suggested that complete MB degradation occurred within $4 \mathrm{~h}$. During the long-term operation for 50 days, $13 \mathrm{~g}$ of $\mathrm{TiO}_{2}$ was added each week to the reactor, expect for the last 2 weeks (days 35-50). Thus the loading of $\mathrm{TiO}_{2}$ was fixed at $1 \mathrm{~g} \mathrm{l}^{-1}$ throughout the operation and this was based on prior reported work [12-14]. Furthermore, the performance at lower $\mathrm{TiO}_{2}$ loadings was investigated in the last 2 weeks. The schematic of the photocatalytic reactor used in the experiment is shown in figure 1 .

The synthetic wastewater was prepared by dissolving $0.056 \mathrm{~g}$ of MB (Sigma-Aldrich) in 201 of deionized water to create $1 \times 10^{-5} \mathrm{M} \mathrm{MB}$ solution [15]. The synthetic wastewater had a dark blue colour with the absorption spectra 
showing the major peak at $664 \mathrm{~nm}$. The photocatalytic efficiency was assessed in terms of the reduction in the peak height, which reflects on the concentration.

The commercial $\mathrm{TiO}_{2}$ particles were analysed by X-ray diffraction (XRD, Panalytical Expert) for determining the mineralogy. The particle sizes and specific surface area were examined using dynamic light scattering (DLS, Malvern Instruments Zetasizer Nano-ZS) and BrunauerEmmett-Teller surface area analysis (BET, Horiba SA-9600), respectively. The indirect band gap of commercial $\mathrm{TiO}_{2}$ par-

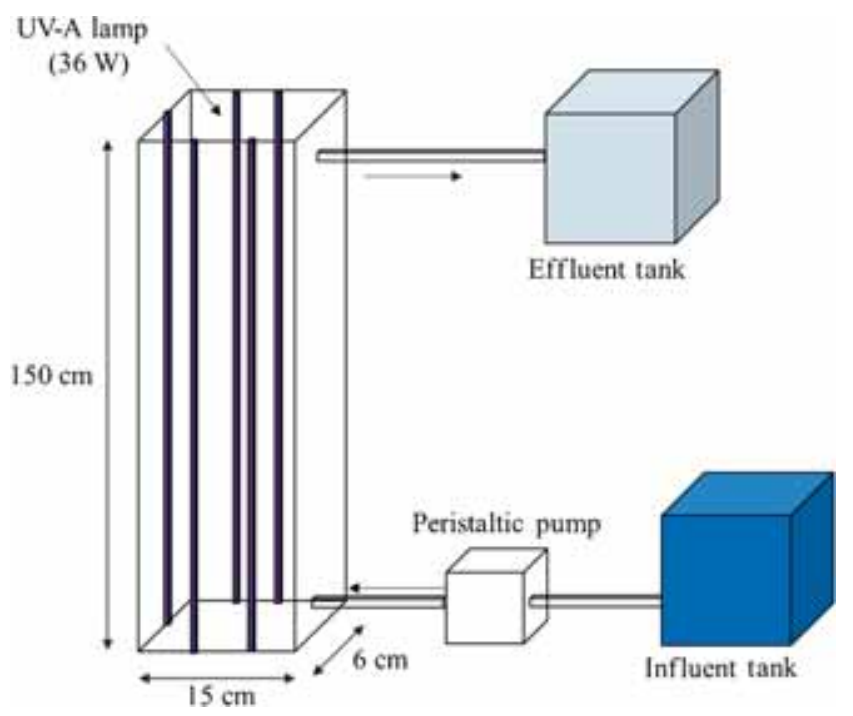

Figure 1. Schematic of the laboratory-scale photocatalytic reactor.

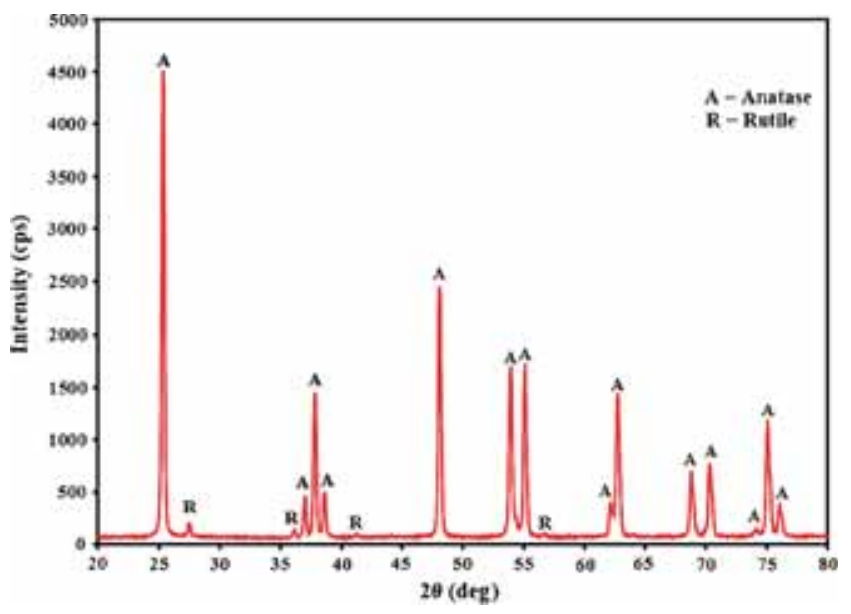

Figure 2. XRD pattern of the commercial $\mathrm{TiO}_{2}$ particles. ticles was determined using a dual-beam spectrophotometer (Perkin Elmer Lambda 35). The absorption spectra of the synthetic wastewater (influent) and treated water (effluent) were measured using a dual-beam spectrophotometer (Mapada UV-6100PC). The $\mathrm{pH}$ and dissolved oxygen (DO) concentrations were measured using a multimeter (Eutech PC700).

\section{Results and discussion}

Figure 2 shows the XRD patterns of the commercial $\mathrm{TiO}_{2}$ particles, which shows that the commercial $\mathrm{TiO}_{2}$ particles were comprised of a mixture of anatase and rutile. However, anatase was the dominant phase $(96 \%)$ with the rest being rutile (4\%) and this was determined from the XRD data [16]. The characteristics of the powders are reported in table 1. It is noted that the optical indirect band gap of $\mathrm{TiO}_{2}$ particles was higher than the generally reported values $(\sim 3.2 \mathrm{eV})$. This is attributed to potential contamination of the particles by silicon, which is known to increase the band gap of $\mathrm{TiO}_{2}$ [17].

Figure 3 presents the changes in the absorption spectra of the MB solutions (effluent) during the first week of operation. After 1 day of treatment, the efficiency of removal was $99.8 \%$. In the subsequent days, the photocatalytic reactor maintained this efficiency with the effluent remaining colourless. At day 7, the effluent became light blue with a slight decrease in the efficiency to $96.8 \%$, and this is attributed to $\mathrm{TiO}_{2}$ accumulation on the wall of the photocatalytic reactor which reduced the transmittance of UV light to the particles. This issue hindered UV activation and hydroxyl radical generation which contributed to a reduction in the efficiency.

Figure 4 shows that the DO contents drops immediately from 6.5 (influent) to 4.0 (in situ) while the $\mathrm{pH}$ also decreases from 8.0 (influent) to 5.5 (in situ) during reactor operation. According to equations (1)-(4), $\mathrm{TiO}_{2}$ was activated by UV to generate pairs of electrons $\left(\mathrm{e}^{-}\right)$and holes $\left(\mathrm{h}^{+}\right)$. Later, the generated holes reacted with $\mathrm{H}_{2} \mathrm{O}$ to form hydroxyl radicals $\left(\mathrm{OH}^{*}\right)$ and hydrogen ions $\left(\mathrm{H}^{+}\right)$. The hydroxyl radicals served as the main oxidant species to degrade the MB molecules, while the generated hydrogen ions acting as a by-product leading to a lowering of the $\mathrm{pH}$ in the reactor. On the other hand, the generated electrons consumed oxygen to create other oxidant species, which led to a significant drop in the DO value in the solution. The photocatalysis mechanism for $\mathrm{MB}$ degradation is suggested to occur as shown in figure 5 [18].

Table 1. Properties of commercial $\mathrm{TiO}_{2}$ particles.

\begin{tabular}{lcccc}
\hline Samples & Anatase-rutile & $\begin{array}{c}\text { Specific surface } \\
\text { area }\left(\mathrm{m}^{2} \mathrm{~g}^{-1}\right)\end{array}$ & $\begin{array}{c}\text { Particle size } \\
(\mathrm{nm})\end{array}$ & $\begin{array}{c}\text { Optical indirect } \\
\text { band gap (eV) }\end{array}$ \\
\hline Commercial $\mathrm{TiO}_{2}$ & $96: 4$ & 9.73 & 400 & 3.74 \\
\hline
\end{tabular}




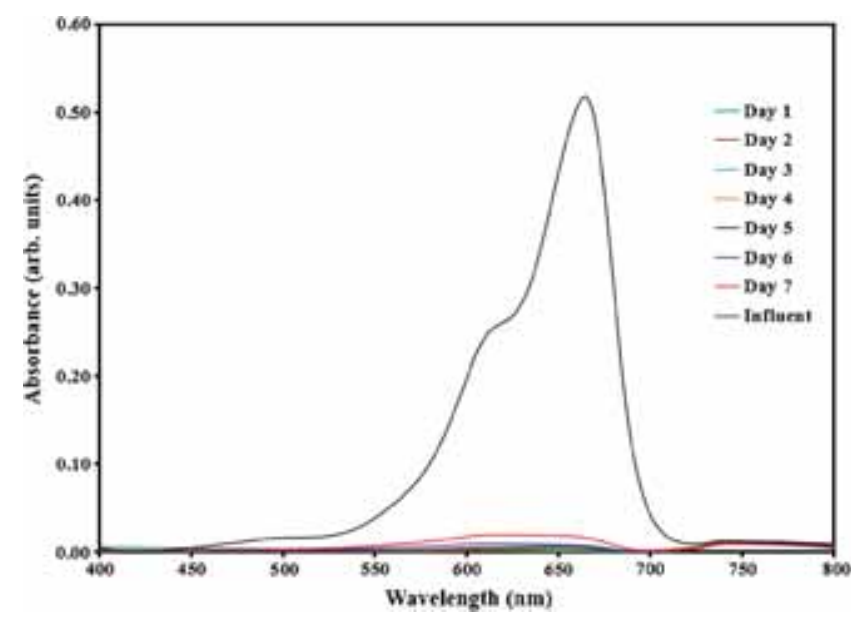

Figure 3. Absorbance spectra of the influent and effluent after 7 days of treatment.

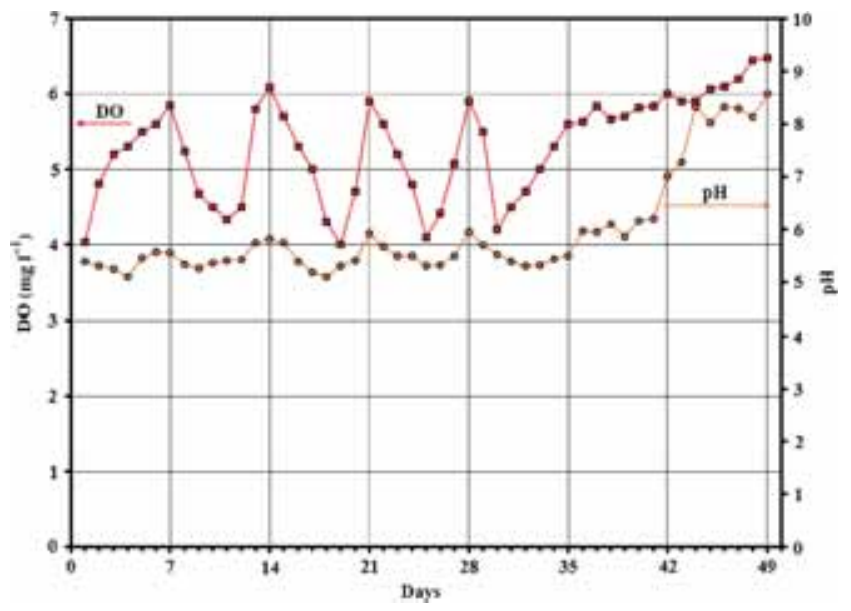

Figure 4. Variations in $\mathrm{DO}$ and $\mathrm{pH}$ during the operation of the reactor over days $1-50$.

$$
\begin{aligned}
& \mathrm{TiO}_{2}+\mathrm{hv} \rightarrow \mathrm{e}^{-}+\mathrm{h}^{+}, \\
& \mathrm{h}^{+}+\mathrm{H}_{2} \mathrm{O} \rightarrow \mathrm{OH}^{\cdot}+\mathrm{H}^{+}, \\
& \mathrm{h}^{+}+\mathrm{OH}^{-} \rightarrow \mathrm{OH}^{\cdot}, \\
& \mathrm{e}^{-}+\mathrm{O}_{2} \rightarrow \mathrm{O}_{2}^{-} .
\end{aligned}
$$

Figure 6 shows the MB removal efficiency over long-term operation for up to 50 days. The removal efficiency was seen to decrease slightly on the final day of each week, particularly, days 7, 14, 21 and 28. However, after the addition of $\mathrm{TiO}_{2}$ on days $8,15,22$ and 29 , the removal efficiency was recovered to $99-100 \%$. In addition, a reduction in $\mathrm{TiO}_{2}$ concentration was found during operation owing to $\mathrm{TiO}_{2}$ wash-out in the effluent. Thus replacement of lost particles was required to maintain the high efficiency of MB degradation. From the 5th week (days 35-50), when $\mathrm{TiO}_{2}$ particles were not added to the reactor, the efficiency decreased gradually and reached a low value of $26 \%$. Thus, for this reactor design, frequent addition and cleaning of $\mathrm{TiO}_{2}$ are necessary to maintain excellent photocatalytic efficiencies.

\section{Conclusion}

In the present work, a photocatalytic reactor was successfully developed for organic compound removal from wastewater. The reactor displayed an excellent MB removal efficiency of $99 \%$. However, the efficiency decreased during long-term operation because of the accumulation of $\mathrm{TiO}_{2}$ particles on the wall of the reactor and the loss of $\mathrm{TiO}_{2}$ in the effluent. To maintain the high performance, sufficient amount of $\mathrm{TiO}_{2}$ particles has to be added on a weekly basis. In the meantime, cleaning is required to reduce $\mathrm{TiO}_{2}$ particle accumulation on the reactor wall to ensure high UV transparency, and

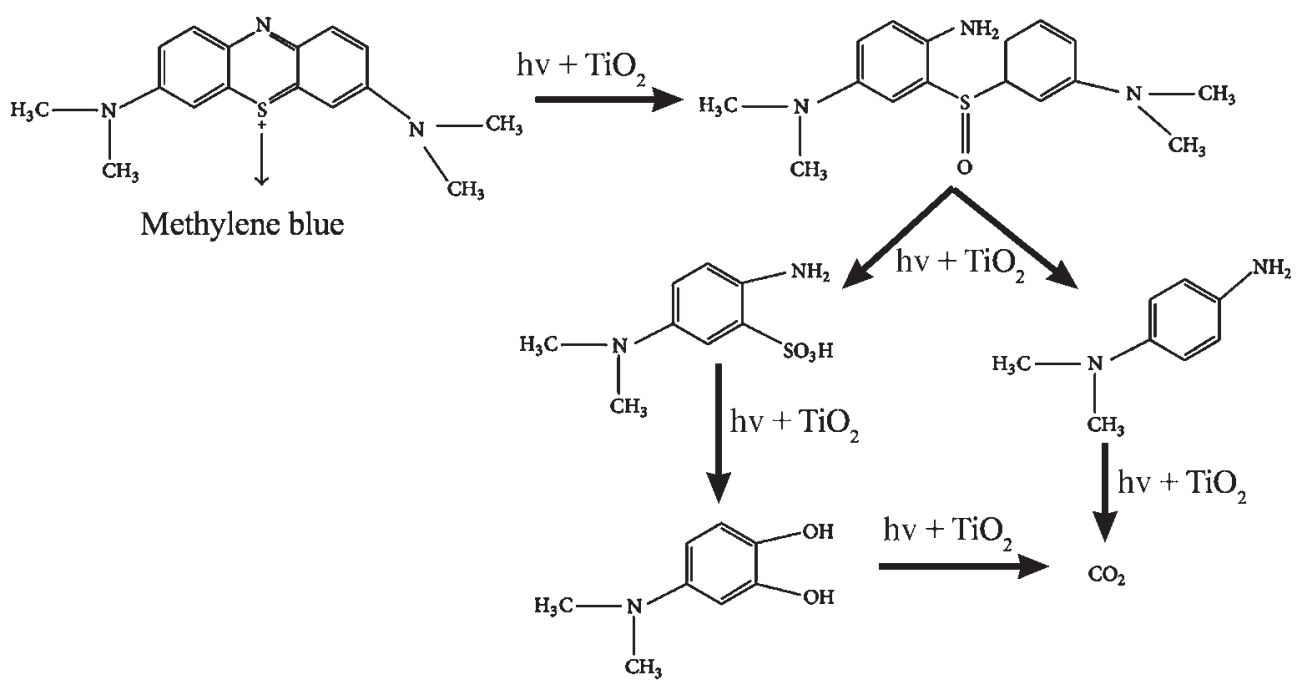

Figure 5. Photocatalytic degradation pathway of methylene blue [18]. 


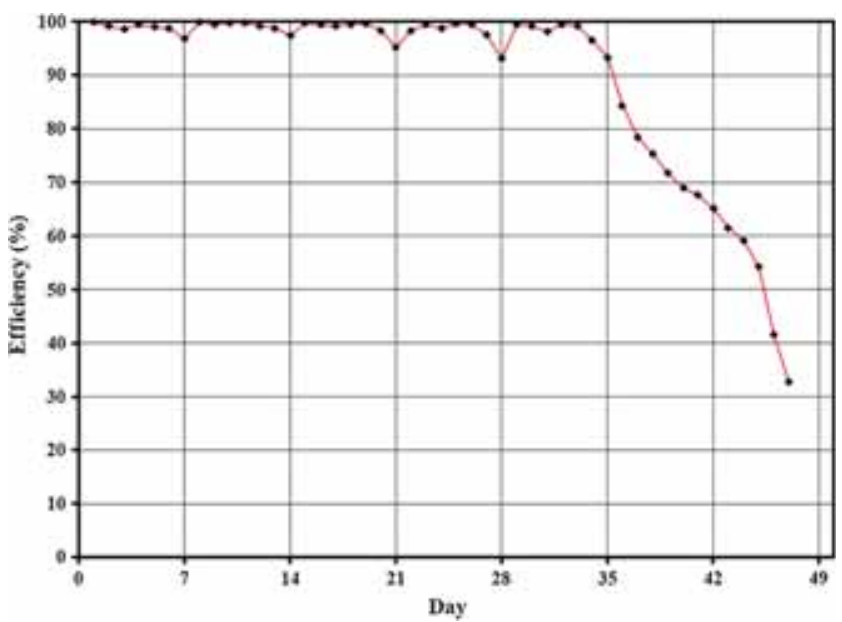

Figure 6. Efficiency of the photocatalytic reactor during operation from days 1 to 50 .

high reactor performance. The current design therefore has some limitations in terms of particle loss and adhesion to the reactor walls. Thus further work is required in understanding the fluid flow behaviour and turbulence in the reactor under continued operation.

\section{Acknowledgements}

We thank Opa Tangpitukkul's scholarship, Siam Kubota Cooperation Co. Ltd., and Naresuan University's research funding for the financial support towards this project.

\section{References}

[1] Chandiran A K, Abdi-Jalebi M, Nazeeruddin M K and Grätzel M 2014 ACS Nano 82261

[2] Xie Y, Jin Y, Zhou Y and Wang Y 2014 App. Surf. Sci. 313 549

[3] Zhao X, Li J, Liu Y, Zhang Y, Qu J and Qi T 2014 Dyes Pigm. 10884

[4] Zhang L, Pan N and Lin S 2014 Int. J. Hydrogen Energy 39 13474

[5] Lyu J, Zhu L and Burda C 2014 Catal. Today 22524

[6] Malato S, Blanco J, Vidal A and Richter C 2002 Appl. Catal. B 371

[7] Byrne J A, Eggins B R, Brown N M D, McKinney B and Rouse M 1998 Appl. Catal. B 1725

[8] Doğan M, Alkan M, Türkyilmaz A and Özdemir Y $2004 J$. Hazard. Mater. 109141

[9] Chen D and Ray A K 1999 Appl. Catal. B 23143

[10] Lin C-P, Chen H., Nakaruk A, Koshy P and Sorrell C C 2013 Energy Procedia 34627

[11] Yuangpho N, Le S T T, Treerujiraphapong T, Khanitchaidecha W and Nakaruk A 2015 Physica E 6718

[12] Ehrampoush M H, Moussavi G H R, GHaneian M T, Rahimi S and Ahmadian M 2011 Iran. J. Environ. Health Sci. Eng. 835

[13] Shaban Y A 2014 Environ. Pollut. 341

[14] Bouna L, Benaissa R and Maury F 2013 Int. J. Photoenergy 2013 Article ID 815473

[15] Mills A and McFarlane M 2007 Catal. Today 12922

[16] Nakaruk A, Kavei G and Sorrell C C 2010 Mater. Lett. 64 1365

[17] Hanaor D A H and Sorrell C C 2011 J. Mater. Sci. 46855

[18] Zuo R, Du G, Zhang W, Liu K, Liu Y, Mei L and Li Z 2014 Adv. Mater. Sci. Eng. 2014 Article ID 170148 